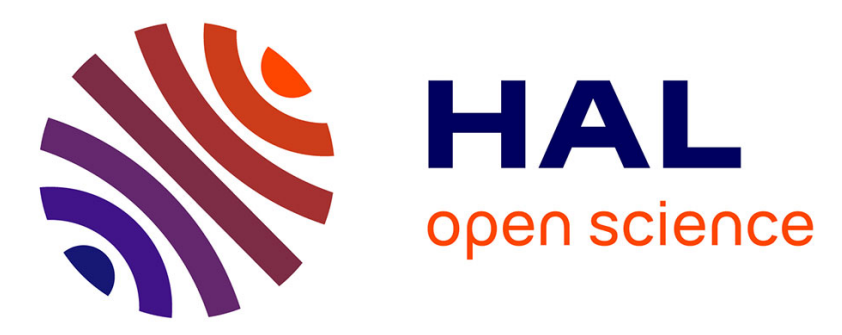

\title{
Crack propagation and size effect in concrete using a non-local damage model
}

\author{
Syed Yasir Alam, Panagiotis Kotronis, Ahmed Loukili
}

\section{To cite this version:}

Syed Yasir Alam, Panagiotis Kotronis, Ahmed Loukili. Crack propagation and size effect in concrete using a non-local damage model. Engineering Fracture Mechanics, 2013, 109, pp.246-261. 10.1016/j.engfracmech.2013.07.009 . hal-01006705

\section{HAL Id: hal-01006705 https://hal.science/hal-01006705}

Submitted on 11 Nov 2019

HAL is a multi-disciplinary open access archive for the deposit and dissemination of scientific research documents, whether they are published or not. The documents may come from teaching and research institutions in France or abroad, or from public or private research centers.
L'archive ouverte pluridisciplinaire HAL, est destinée au dépôt et à la diffusion de documents scientifiques de niveau recherche, publiés ou non, émanant des établissements d'enseignement et de recherche français ou étrangers, des laboratoires publics ou privés. 


\title{
Crack propagation and size effect in concrete using a non-local damage model
}

\author{
Syed Yasir Alam ${ }^{\mathrm{a}, \mathrm{b}, *}$, Panagiotis Kotronis ${ }^{\mathrm{b}}$, Ahmed Loukili ${ }^{\mathrm{b}}$ \\ ${ }^{a}$ National University of Computer and Emerging Sciences, Department of Civil Engineering, Lahore, Pakistan \\ ${ }^{\mathrm{b}}$ L'UNAM Université, Ecole Centrale de Nantes, GeM (Research Institute of Civil Engineering and Mechanics), CNRS UMR 6183, 1 rue de la Noë, BP 92101, 44321 \\ Nantes Cedex 3, France
}

\begin{abstract}
Size effect is a major issue in concrete structures. Experimental and numerical investigations on the influence of size effect on crack opening, crack length and crack propagation are presented in this paper. An isotropic non-local strain softening damage constitutive law is adopted for the numerical model. The material characteristic length is calibrated using an optimization algorithm and a post-processing method is chosen to obtain information on cracking. Numerical global and local results are compared with the experimental data and conclusions are drawn on the advantages and limitations of the adopted modelling strategy to reproduce size effect in concrete structures.
\end{abstract}

\section{Introduction}

It is well known that strains in concrete under severe loadings tend to localize in specific areas of finite dimensions. Constitutive laws without an internal length parameter predict this dimension to be zero, with vanishing energy dissipation at failure. The numerical response is no longer objective but depends on the finite element mesh (number and orientation of the elements) [1]. Several solutions exist in the literature: the use of constitutive laws that introduce indirectly an internal length by involving gradients of an internal variable like plastic strain [2,3] or damage [4] or the use of higher order media (media with microstructure) [5-7]. An alternative way is to introduce explicitly an internal length in the model following the non-local damage theory [8].

Another problem when studying fracture within a continuum mechanics approach is the reproduction of cracks including inception, location, propagation and opening. Damage mechanics models, often used for concrete, successfully predict the onset and location of failure but are unable to describe crack discontinuities and crack openings. The use of specific postprocessing procedures on the continuum damage fields is a possible solution (see for example the French national project ANR MEFISTO [9]).

Different techniques can be used to determine crack openings. Mindess [37] proposed that any crack with a width more than $6 \mu \mathrm{m}$ could be considered as a macrocrack. However, in the Fracture Process Zone (FPZ) several microcracks are present

* Corresponding author at: National University of Computer and Emerging Sciences, Department of Civil Engineering, Lahore, Pakistan. Tel.: +92 3314822469.

E-mail addresses: yasir.alam@nu.edu.pk, syedyasiralam@gmail.com (S.Y. Alam). 


\section{Nomenclature}

d scalar damage variable

$d_{a} \quad$ maximum size of aggregates

$d_{t} \quad$ scalar damage variable in tension

$d_{c} \quad$ scalar damage variable in compression

$l_{c} \quad$ internal length of the non-local continuum

l/D span to depth ratio

$A_{c} \quad$ material parameter in the damage evolution law (compression)

$A_{t} \quad$ material parameter in the damage evolution law (traction)

$B$ thickness of beam

$B_{c} \quad$ parameter in the damage evolution law (compression)

$B_{t} \quad$ parameter in the damage evolution law (traction)

$B f_{t} \quad$ normalization parameter for ordinate in the normalized size effect curve

CMOD Crack Mouth Opening Displacement

COD Crack Opening Displacement

$D \quad$ height of beam

$D_{0} \quad$ normalization parameter for abscissa in the normalized size effect curve

E Young's modulus

FPZ Fracture Process Zone

$F_{\max } \quad$ maximum force attained by the specimen

$\vec{P} \quad$ vector of unknown model parameters

$R_{\exp }^{i} \quad$ experimental response for the size $i(i \in[1,2,3])$

$R^{i}(\vec{P}) \quad$ numerical response for the size $i(i \in[1,2,3])$

$V_{r}(x) \quad$ representative volume at point $x$

\section{Greek symbols}

$\alpha_{t} \quad$ weight coefficient to combine damage variables in tension and compression

$\varepsilon_{x x} \quad$ volumetric strain component in axial direction

$\varepsilon_{y y} \quad$ volumetric strain component in vertical direction

$\varepsilon_{x y} \quad$ deviatoric strain

$\tilde{\varepsilon} \quad$ positive equivalent measure of strain

$\bar{\varepsilon} \quad$ non-local strain

$\delta_{i j} \quad$ Kronecker symbol

$\kappa_{D 0} \quad$ initial damage threshold parameter in the damage evolution law

$\Omega \quad$ volume of the structure

$\kappa$ damage threshold parameter in the damage evolution law

$\psi \quad$ weight function for the computation of non-local strains

$\tau(\vec{P}) \quad$ functional to minimize in the Levenberg-Marquardt algorithm

$v_{0} \quad$ Poison's ratio

and sometimes are isolated from the macrocrack [37,38]. The crack openings of the individual microcracks are very small (sometimes less than a micrometre) and are very difficult to measure as microcracks are densely spread in this zone. In fact, it is more interesting to quantify the cumulative crack openings of the microcracks present in the FPZ that to measure the crack opening of the individual microcracks. This can be done using X-ray or Acoustic Emission (AE) techniques that can follow the crack formation inside the material [25,39]. Otsuka and Date [25] have shown the similitude between data recorded with the X-ray technique and AE events. The digital image correlation (DIC) technique is also sometimes used to determine crack profiles in concrete [40,41]. It provides high-resolution measurements of the displacement field on the specimen surfaces from which crack openings can be easily determined. With this method, discontinuities are first detected in the displacement fields and then the relative displacements are calculated across the opposite sides of the crack and along its full length [10-12].

In this paper, we study crack propagation and size effect in concrete specimens combining some of the above experimental and numerical tools. More specifically, three point bending tests performed at Ecole Centrale Nantes are presented and crack openings are estimated with the DIC technique [10]. An isotropic non-local damage model is used for the numerical simulations and an optimization algorithm is used for the calibration of the material parameters, as suggested in [13]. In addition however, not only global but also local variables (damage distribution and crack opening profiles) are confronted to the experimental results. Parametrical studies are presented and important interesting conclusions are drawn about the ability and limitations of the chosen non-local model to reproduce crack propagation and size effect in concrete specimens. 


\section{Three point bending tests}

\subsection{Specimens and experimental procedure}

Three sizes of concrete beam specimens were designed: while geometrically similar in two dimensions (length and depth), their cross sectional heights $D$ were taken equal to 100, 200 and $400 \mathrm{~mm}$ respectively. Their cross sections were rectangular, the thickness $B$ equal to $100 \mathrm{~mm}$ and the span to depth ratio $(l / D)$ equal to $3: 1$. The beams were notched at mid-span with a notch length $a$ that varied proportionally to the size of the beam (a/D was kept equal to 0.2). The design followed the RILEM recommendations for size effect [14]. The beams are designated hereafter as D1, D2 and D3 (for small, medium and large size).

The coarse aggregate used in the concrete mixture had a maximum size of $d_{a}=20 \mathrm{~mm}$. Tests to define the axial compressive strength and the Young's modulus were performed and the average values at 28 days were found $45 \mathrm{MPa}$ and $38 \times 10^{3} \mathrm{MPa}$ respectively.

The bending tests were performed with a controlled notch opening displacement (or Crack Mouth Opening Displacement, CMOD) rate of $0.05 \mu \mathrm{m} / \mathrm{s}$. This type of control allows obtaining a gradual increase in the crack openings and at a later stage (post-peak regime) a steady decrease of the load bearing capacity.

The DIC method was applied and images were continuously obtained during the whole loading branch. For each beam size, two series of tests were performed. In the first, the cameras were focused on an area of approximately $60 \times 100 \mathrm{~mm}$ above the notch of the beam. For this resolution, 1 pixel in the image represents an approx. $35 \mu$ m square on the specimen. In the second, the cameras were mounted at a certain distance required to monitor the full height of the specimen. The resolutions obtained were: 1 pixel $=105 \mu \mathrm{m}$ for the D1 beam, 1 pixel $=180 \mu \mathrm{m}$ for the D2 and 1 pixel $=288 \mu \mathrm{m}$ for the D3. Displacement fields were finally calculated using the DIC technique.

\subsection{Experimental results}

In order to validate the DIC setup, Crack Opening Displacements (COD) were calculated from the digital images considering the sum of the horizontal displacements of two points at a distance $5 \mathrm{~mm}$ on either side of the crack. This simplified method seems to provide satisfactory results for the case when the structural behavior is mainly 1D (i.e. beam elements) and the DIC technique can clearly identify the boundaries of the (localized) crack (a similar method is applied in Section 4.3 to calculate the numerical COD). In order to validate the chosen procedure, the CMOD was thus determined and compared with experimental measurements from a CMOD clip gauge. The two measurements showed a good agreement with a variation in the range of $\pm 3 \mu \mathrm{m}[15]$.

The COD issued from DIC at different locations along the crack length (i.e. along the height of the specimen) were calculated following the previous procedure for the three specimens and for different levels of loading. The results of the D2 specimen are presented hereafter (Fig. 1): Crack opening profiles on both sides ( $a$ and b) of the specimen have the same slope and are similar in the pre-peak but also in the post-peak regime. Conclusions were identical for the specimens D1 and D3 [15].

From the crack opening profiles, the crack length (measured from the notch tip) can be approximately located considering where the COD becomes equal to zero (i.e. crack closure). Actually, the crack tip is "blurred" by microcracking in the Fracture Process Zone (FPZ) and the COD gives the cumulative crack openings of all the microcracks in the FPZ. Therefore, the crack length measured in this way is the length of the macrocrack plus the length of the FPZ where microcracks exist. This indicator can be very useful to study the durability of concrete structures, especially for cases where minor cracks can cause serious damage.

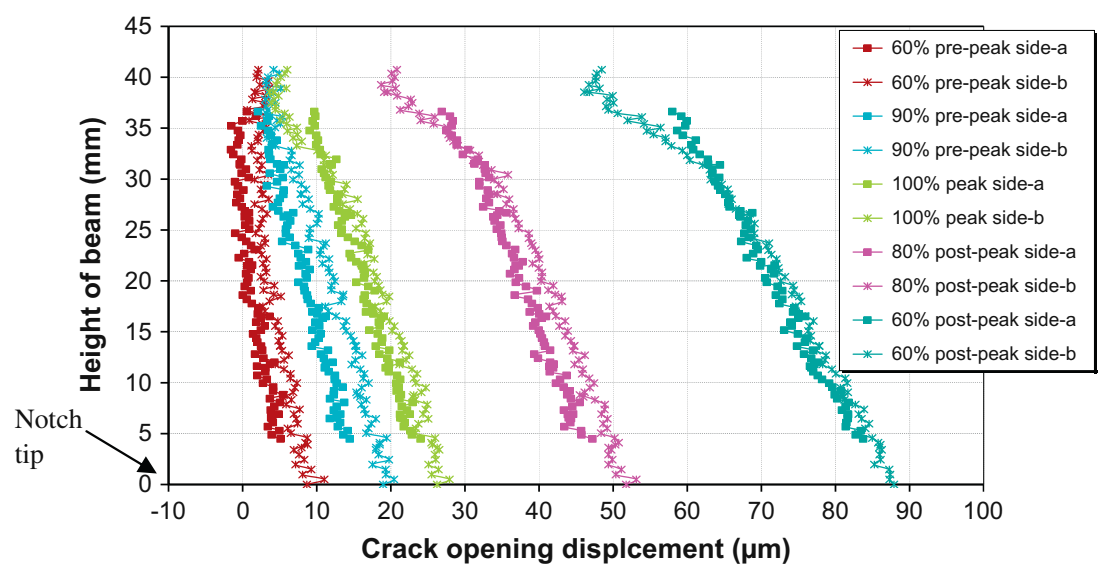

Fig. 1. Crack opening profile at different loading steps on two sides (a and b) of D2 specimen. 
The relative crack length is defined hereafter as the ratio of the crack length with the height of the specimen from the notch tip. Fig. 2 represents its evolution for different levels of loading and for all the specimens. It can be seen that for all specimens the formation of crack starts before the maximum load is reached. For the smaller specimen D1, the crack initiates at low load level. For the larger specimen D3, the crack appears just before the peak load.

The evolution of the relative crack of the D1 specimen can be divided in three stages: the first stage is situated between the crack initiation and just after the peak load (i.e. from $50 \% F_{\max }$ in the pre-peak to $95 \% F_{\max }$ in the post-peak regime). Within this stage, the crack growth is smooth. In the second stage i.e. from $95 \% F_{\max }$ to $80 \% F_{\max }$ in post-peak regime, the relative crack grows suddenly multiplying by two its value. In the last stage, evolution is relatively slow. It can also be observed that the relative crack length for the D1 specimen is bigger compared to D2 and D3 and this for all the loading phases. This is an evidence of a significant size effect on the crack length. Finally, according to the original version of the Bazant Size Effect Law [16] the relative crack length at peak load should be constant for concrete specimens of varying sizes. This assumption is not confirmed with the above experimental study.

During loading, microcracks first arise which change gradually into dominant distinct macroscopic discrete cracks up to rupture. Thus, a fracture process is generally subdivided into two main stages: appearance of narrow localized zones of intense deformation (including microcracks) and occurrence of discrete macrocracks. The zone of strain localization is identified experimentally (Figs. 3 and 4). Only the axial component $\left(\varepsilon_{x x}\right)$ is provided, the magnitudes of the other components ( $\varepsilon_{y y}$ and $\varepsilon_{x y}$ ) being significantly (5-10 times) smaller. Nevertheless, the strain pattern is obtained using continuum mechanics laws. Therefore, only the strains before the appearance of a macrocrack are meaningful.

It should be also noticed that the width of the strain localization zone in the pre-peak regime remains (almost) constant (approximately $100 \mu \mathrm{m}$ for D1 and D2, slightly greater for D3, Fig. 4). The width of the strain localization zone is comparable to results found in the literature where DIC technique is used e.g. in the experiments of Skarzynski et al. [42]. However, it is also possible that the localization zone (measured on the concrete surface in our experiments) is significantly larger inside the specimen. The width of the localization zone increases as the load approaches the peak and further increases in the postpeak regime. This observation is valid for all the specimen sizes.

\section{Numerical modelling of crack propagation}

In this section, the non-linear behavior of D1, D2 and D3 specimens is reproduced using the non-local formulation of Mazars isotropic continuum damage mechanics model [8,17] and the finite element code Cast3M [18].

\subsection{Constitutive law}

An isotropic scalar damage model is adopted

$$
\varepsilon_{i j}=\frac{1+v_{0}}{E(1-d)} \sigma_{i j}-\frac{v_{0}}{E(1-d)} \sigma_{k k} \delta_{i j}
$$

where $d$ is the damage variable with values varying from 0 to 1 (for $d=1$, the material is assumed completely damaged). $v_{0}, E$ and $\delta_{i j}$ are the Poison's ratio, Young's modulus and Kronecker symbol respectively.

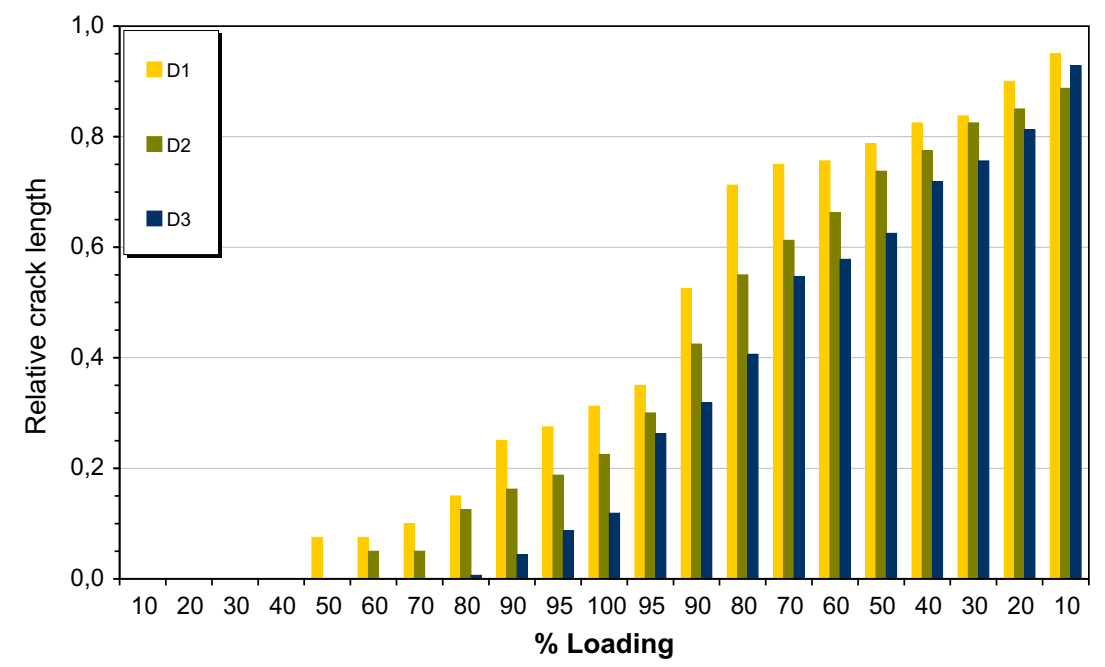

Fig. 2. Evolution of relative crack length with loading steps for D1, D2 and D3 specimens (experimental results). 


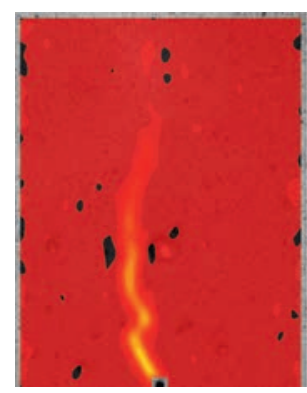

(D1)

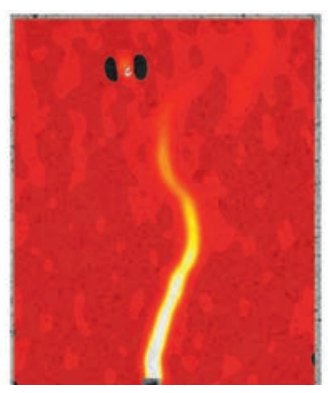

(D2)

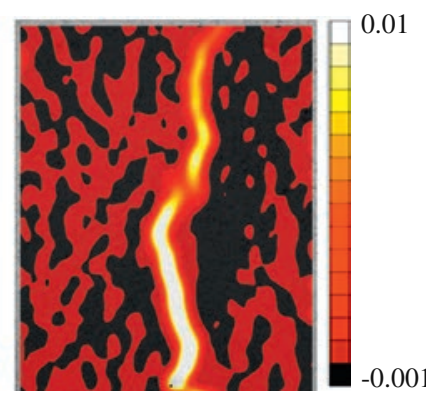

(D3)

Fig. 3. Experimental Green Lagrange strain fields $\left(\varepsilon_{\mathrm{xx}}\right)$ in D1, D2 and D3 specimens at peak load.

The damage loading function is defined as:

$$
f(\tilde{\varepsilon}, \kappa)=\tilde{\varepsilon}-\kappa
$$

where $\tilde{\varepsilon}$ is a positive equivalent measure of strain and $\kappa$ is a threshold value. For the equivalent strain, Mazars [17] proposed the following form:

$$
\tilde{\varepsilon}=\sqrt{\sum_{i=1}^{3}\left(\left\langle\varepsilon_{i}\right\rangle_{+}\right)^{2}}
$$

where $\varepsilon_{i}$ are the principal strains.

In order to capture the difference on the behavior in tension and compression, Mazars [17] proposed to split the damage variable into two parts:

$$
d=\alpha_{t} d_{t}+\left(1-\alpha_{t}\right) d_{c}
$$

where $d_{t}$ is the damage variable in tension and $d_{c}$ in compression. They are combined using a weight coefficient $\alpha_{t}$ defined as a function of the principal strains $\varepsilon_{i j}^{t}$ and $\varepsilon_{i j}^{c}$ due to positive and negative stresses respectively.

The evolution of damage is provided in an integrated form:

$$
d_{t, c}=1-\frac{\kappa_{D 0}\left(1-A_{t, c}\right)}{\kappa}-A_{t, c} \exp \left(-B_{t, c}\left(\kappa-\kappa_{D 0}\right)\right)
$$

where $\kappa_{D 0}, A_{t}, B_{t}, A_{c}$ and $B_{c}$ are model parameters. Detailed information on this damage mechanics law can be found in [17].

\subsection{Non-local formulation}

The non-local damage mechanics theory [8] proposes to replace the equivalent strain $\tilde{\varepsilon}$ with an average value defined as:

$$
\bar{\varepsilon}(x)=\frac{1}{V_{r}(x)} \int_{\Omega} \psi(s) \tilde{\varepsilon}(s+x) d s \quad \text { with } V_{r}(x)=\int_{\Omega} \psi(s) d s
$$

where $\Omega$ is the volume of the structure, $V_{r}(x)$ is the representative volume at point $x$, and $\psi(s)$ is the weight function:

$$
\psi(x)=\exp \left(-\frac{4|s|^{2}}{l_{c}^{2}}\right)
$$

where $l_{c}$ is the internal length of the non-local continuum, related to the width of the FPZ [19].

\subsection{Mesh discretization}

A plane stress assumption is adopted. Two dimensional quadrilateral elements with four gauss points are used for the mesh and the size of the elements is kept small in the area close to the notch where damage is expected. The lower limit of the element size verifies the criterion that the characteristic length $l_{c}$ should be at least three times the size of the element. The finite element meshes of D1, D2 and D3 beams are presented in Fig. 5. The notch tip of the beams is modelled as an arc to avoid any singularity on the mechanical fields.

\subsection{Boundary conditions}

Due to the symmetric boundary conditions and in order to reduce the computational demands, only one half of the beams are modelled (thus, the model can reproduce only symmetric solutions). The non-local damage formulation of the Mazars 

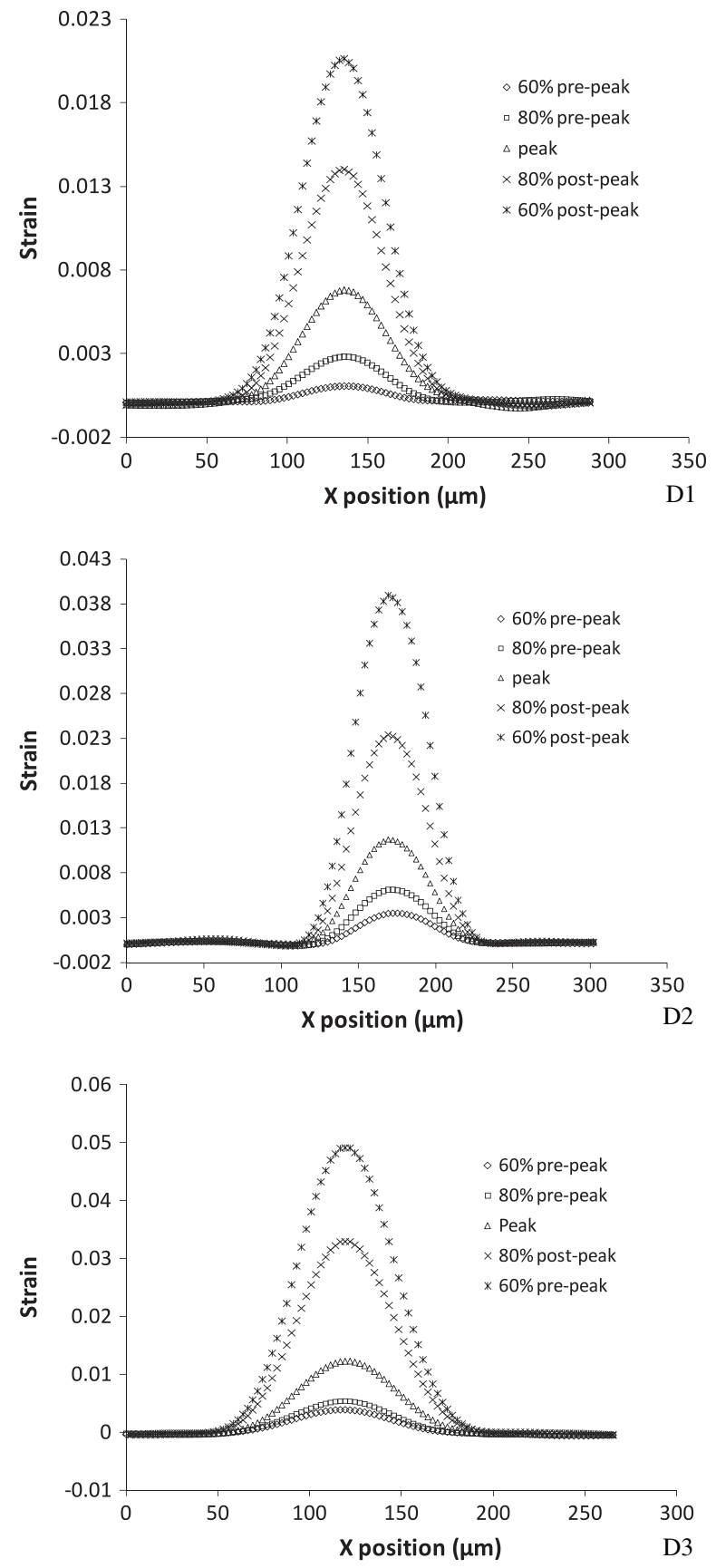

Fig. 4. Experimental strain profiles at the front of the notch in D1, D2 and D3 beams.

damage model is considered in the central part of the beams (represented in red ${ }^{1}$ in Fig. 5); the behavior of the other part is assumed linear elastic. This also helps reducing considerably the time of the simulation. The area of the beam modelled with the non-local damage law is proportional to their height.

Loading is applied as an increment of the vertical displacement of a rigid plate (assuming a linear elastic law and a Young's modulus ten times greater than that of concrete) fixed at the top right end of the beam (see Fig. 6). To reproduce the symmetric boundary conditions, all the displacements in the horizontal direction (X-displacement) of the right side of the beam above the notch are blocked. The vertical displacement of the articulation at the left side of the beam is also restrained.

\footnotetext{
${ }^{1}$ For interpretation of color in Fig. 5, the reader is referred to the web version of this article.
} 


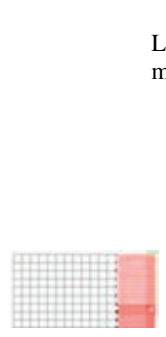

(D1)

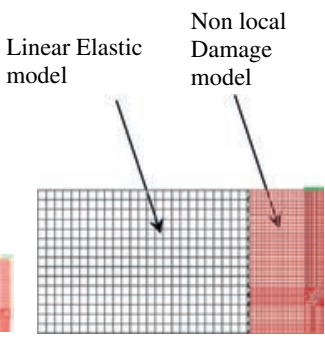

(D2)

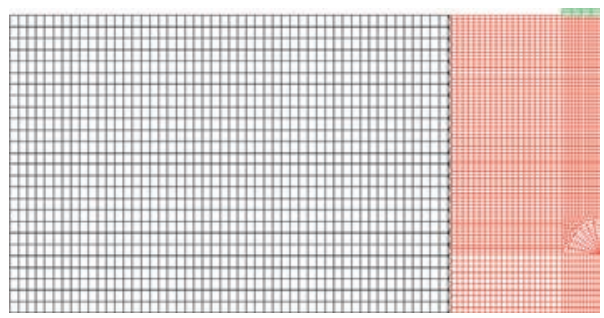

(D3)

Fig. 5. Finite element meshes for D1, D2 and D3 beams.

In the following sections, global results are presented in the form of Force-CMOD curves. The force is calculated as the vertical reaction at the bottom left support of the beam and CMOD as the horizontal displacement at the bottom right corner (see Fig. 6).

\subsection{Determination of the non-local damage model parameters}

Two sets of parameters have to be identified for the non-local formulation of the Mazars law i.e. the parameters which are related with the original, local equations of the model [17] and the spatial parameter $l_{c}$ governing the interaction of the material points. These two sets of parameters are closely related to each other and should be appropriately determined to provide the non-local model with a response consistent with the required macroscopic material behavior and the local fracture characteristics. The existence of the spatial parameter requires the solution of a boundary value problem [13]. This is totally different from the local approach, where the constitutive behavior of the model can be calibrated directly from the experimental data.

This issue has been discussed by several researchers. Their studies can be generally grouped into two classes: those based directly on a numerical inverse analysis of the experimental results and those exploiting the correspondence between the cohesive crack model and the crack band model. In the first category, automatic calibration procedures are generally employed using different optimization algorithms [13,20,21]. In the second category, the correspondence between the cohesive crack model and the crack band model along with a relationship between the internal length parameter of the non-local model and the width $h$ of the fracture process zone is exploited (e.g. in non-local and gradient models used by De Borst and Pamin [22] and Di Prisco and co-workers [23]).

In the following, an optimization algorithm is applied based on an inverse analysis on the size effect experiments presented earlier in this paper. The general procedure is the one proposed by Le Bellego and co-workers [13]. The eight model parameters to identify are assembled in the following vector:

$$
x^{T}=\left[\begin{array}{lllllllll}
E & v & \kappa_{D 0} & A_{t} & B_{t} & A_{c} & B_{c} & \beta & l_{c}
\end{array}\right]
$$

The Young's modulus $E$ and the Poison's ratio $v$ can be determined from standard uni-axial tests. $\kappa_{D 0}$ is the damage threshold, $A_{t}$ and $B_{t}$ are the parameters of the model relative to the damage evolution under tensile loadings and $A_{c}$ and $B_{c}$ under compressive loadings; $\beta$ is linked to the shear response. For the case of three point bending tests, traction is more important than compression and shear. The parameters $A_{c}, B_{c}$ and $\beta$ are therefore defined considering typical values (1.2, 1500 and 1.06 respectively). The internal length $l_{c}$ characterizes the material connectivity and the fracture process zone, and needs to be determined. The vector of unknown material parameters thus becomes:

$$
P^{T}=\left[\begin{array}{llll}
\kappa_{D 0} & A_{t} & B_{t} & l_{c}
\end{array}\right]
$$

An initial set of the four unknown model parameters is first determined by manual calibration on the experimental Force-CMOD curves. The medium size (D2) beam is chosen for the initial fitting. Le Bellego and co-workers [13] proposed

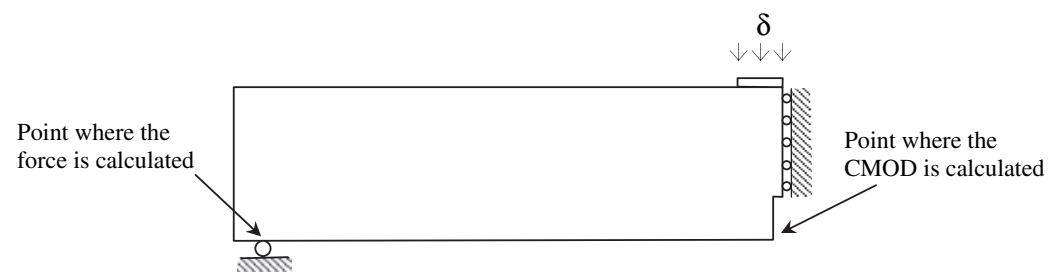

Fig. 6. Boundary conditions. 
Table 1

Initial values of the non-local model parameters (manual calibration).

\begin{tabular}{lllll}
\hline & $\kappa_{D 0}$ & $A_{t}$ & $B_{t}$ & $l_{c}(\mathrm{~mm})$ \\
\hline Initial set -1 & $3.37 \times 10^{-5}$ & 0.83 & 8345 & 40 \\
Initial set -2 & $3.26 \times 10^{-5}$ & 0.81 & 5442 & 20 \\
\hline
\end{tabular}

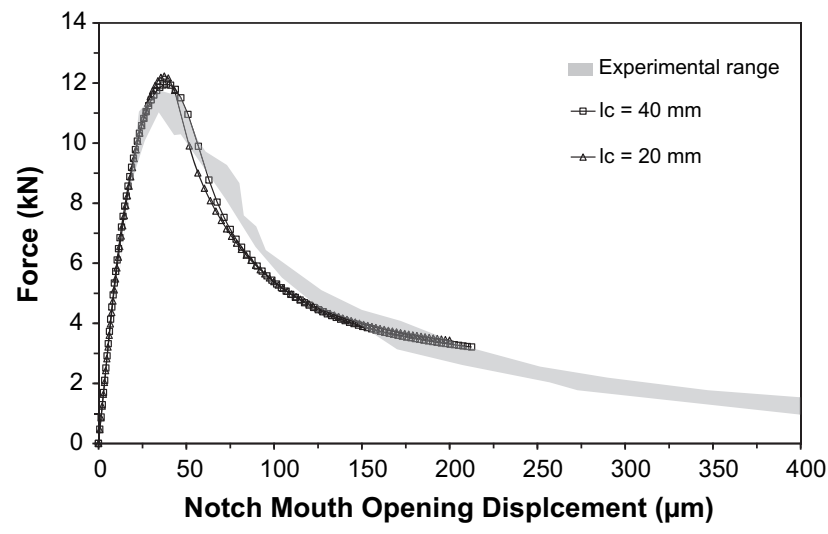

Fig. 7. Force-CMOD curve for the D2 beam (manual calibration).

Table 2

Non-local model parameters (optimization algorithm).

\begin{tabular}{llll}
\hline & $\kappa_{D 0}$ & $A_{t}$ & $B_{c}(\mathrm{~mm})$ \\
\hline Set -1 & $2.67 \times 10^{-5}$ & 0.80 & 13,665 \\
Set -2 & $2.90 \times 10^{-5}$ & 0.74 & 99.1 \\
\hline
\end{tabular}

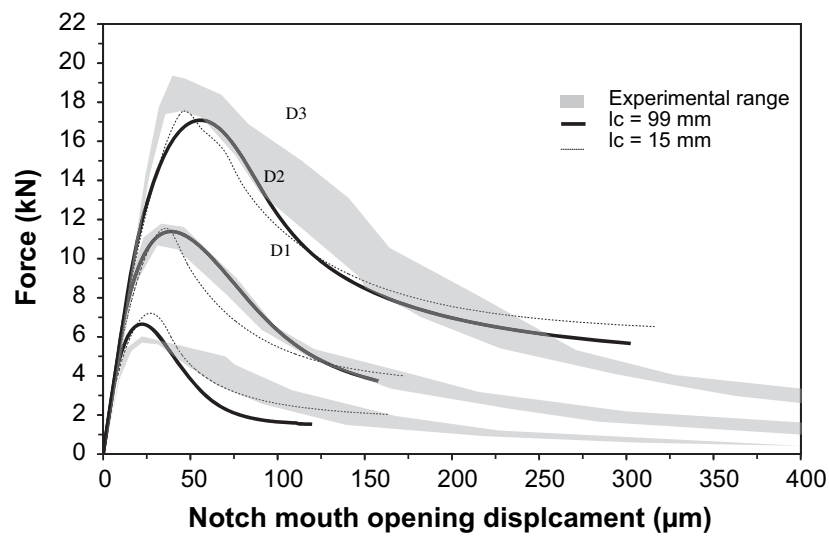

Fig. 8. Force-CMOD curves for the D1, D2 and D3 beams (optimization algorithm)

that the initial value of $l_{c}$ should be related to the size of the FPZ and can be taken between $2 d_{a}$ to $5 d_{a}$, where $d_{a}$ is the maximum size of aggregates. In this study, two different values of $l_{c}$ are tested and two initial sets of parameters are obtained as shown in Table 1 . In the first set, the internal length $l_{c}$ equals $2 d_{a}$ and in the second $l_{c}$ equals $d_{a}$. The Force-CMOD curves for both sets are presented in Fig. 7 .

Although the manual calibration provides acceptable global results, local phenomena may not be correctly reproduced. Furthermore, application to specimens of different sizes could not be accurate because the size effect may not be well captured. Therefore and as suggested in [13], an optimization procedure is applied: the initial sets are adjusted on the Force-CMOD responses of the three specimens simultaneously using the Levenberg-Marquardt algorithm that performs a minimization of the following functional $\tau(\vec{P})[13]$ : 

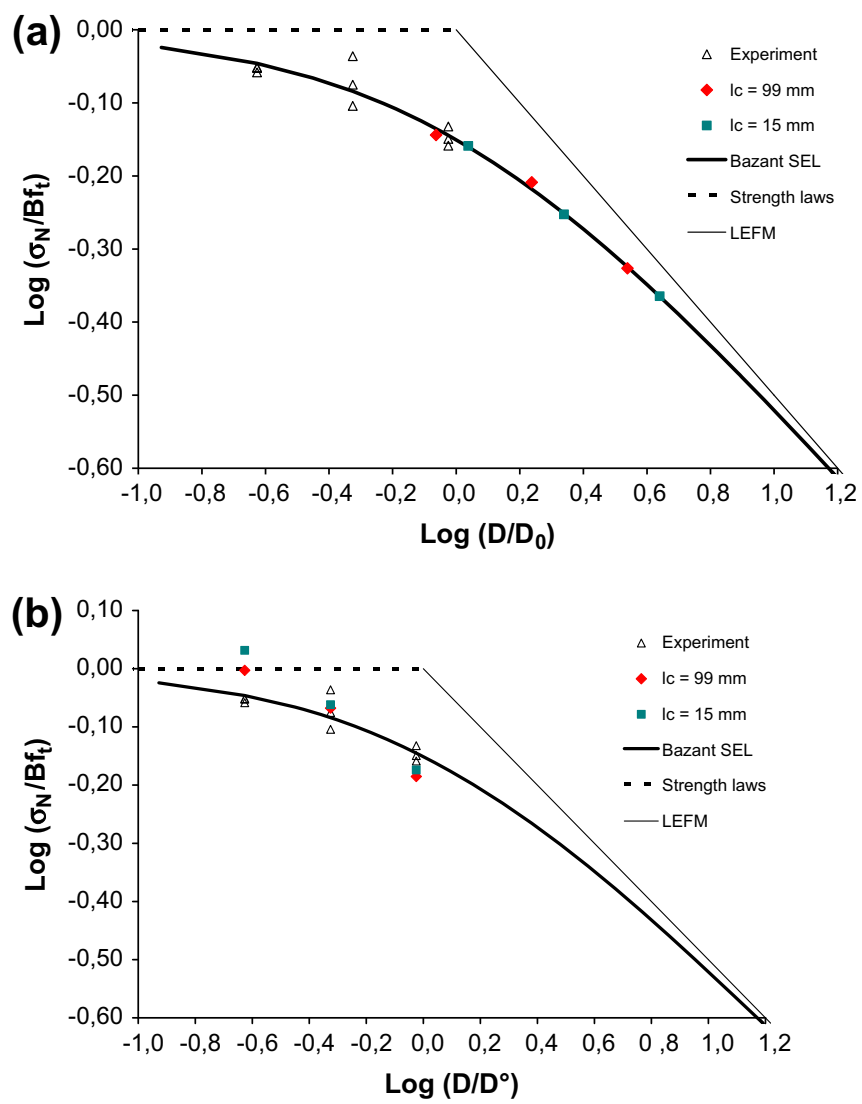

Fig. 9. Size effect plots. Experimental and numerical data normalized using parameters coming from (a) computation (b) experiments.

Table 3

Size independent fracture parameters.

\begin{tabular}{lccc}
\hline Parameter set & $D_{0}(\mathrm{~mm})$ & $B f_{t}(\mathrm{MPa})$ & $G_{f}(\mathrm{~N} / \mathrm{m})$ \\
\hline$l_{c}=99 \mathrm{~mm}$ & 115.68 & 4.19 & 31.5 \\
$l_{c}=15 \mathrm{~mm}$ & 91.61 & 4.69 & 31.4 \\
Experiment & 423.3 & 3.02 & 68.4 \\
\hline
\end{tabular}

$l_{c h}^{*}$ is the material characteristic length according to Hillerborg [34].

$$
\tau(\vec{P})=\frac{1}{2} \sum_{\text {size }=1}^{3}\left[\sum_{\text {measured data points }}\left\{\left(\frac{R^{i}(\vec{P})-R_{\text {exp }}^{i}}{\operatorname{Max}\left(R_{\text {exp }}^{i}\right)}\right)^{T}\left(\frac{R^{i}(\vec{P})-R_{\text {exp }}^{i}}{\operatorname{Max}\left(R_{\text {exp }}^{i}\right)}\right)\right\}\right]
$$

where $R_{\text {exp }}^{i}$ is the "experimental response" for the size $i(i \in[1,2,3]), R^{i}(\vec{P})$ is the "numerical response" and $\vec{P}$ is the vector of model parameters.

Several definitions can be used for the "experimental" and "numerical" responses. Hereafter, calibration is done using the stresses corresponding to 100 values of CMOD equally spaced and covering the whole experimental data range (it is important to cover the whole experimental post-peak regime in order to reproduce crack propagation but also for durability studies). Because the responses are in different scales for the three specimens, it is necessary to express them in a nondimensional way (or to use a weighted functional). This is the reason why the error between the numerical and experimental responses is divided by the maximal experimental response relative at each size. Cast3M needed five iterations to minimize the functional (the error reached a minimum and remained constant afterwards).

Table 2 presents the model parameters calculated by the optimization procedure for both sets of the initial parameters. The relative global responses are given in Fig. 8. It can be observed that the two sets provide the correct (experimental) value of peak load for the D2 beam. For D1 and D3 beams however, the peak loads are not satisfactory. Furthermore, calibration is relatively poor in the post-peak regime. 


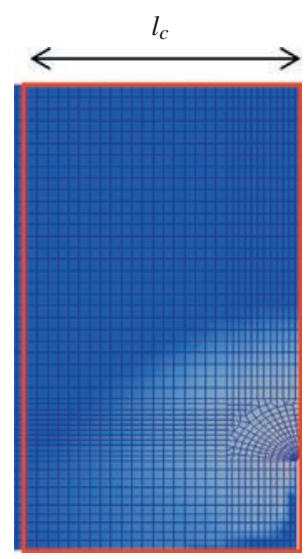

(a)

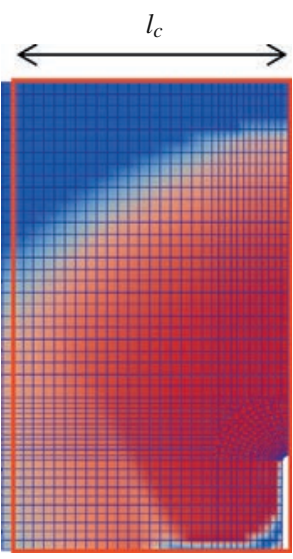

(b)

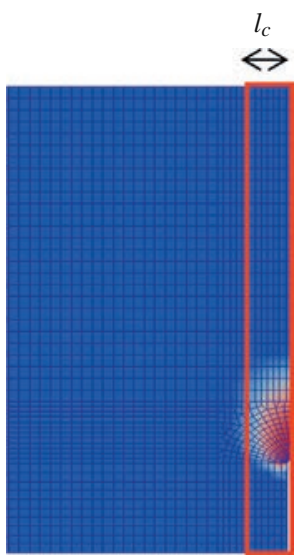

(c)

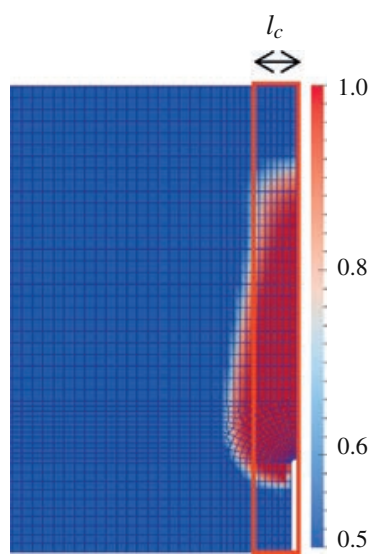

(d)

Fig. 10. Evolution of the internal damage variable $d$ for the D2 beam (a) at peak load, $l_{c}=99 \mathrm{~mm}$, (b) at the tail end of the F-CMOD curve, $l_{c}=99 \mathrm{~mm}$, (c) at peak load, $l_{c}=15 \mathrm{~mm}$ and $(\mathrm{d})$ at the tail end of F-CMOD curve, $l_{c}=15 \mathrm{~mm}$.

\section{Discussion}

In the previous section, calibration of the non-local damage model is performed using an optimization algorithm. Input to the algorithm is the initial set of model parameters calibrated manually using the medium size beam. Consequently in Fig. 8, numerical results are better calibrated for the D2 beam compared to the D1 and D3 beams. The performance of the optimization procedure is limited and results are highly dependent on the initial parameter sets. Two manually calibrated initial sets converge to two different solutions with internal lengths varying from $15.4 \mathrm{~mm}\left(0.77 d_{a}\right)$ to $99.1 \mathrm{~mm}\left(4.95 d_{a}\right)$, thus not always inside the range proposed in [13]. In addition, a converged single set of parameters that provides an acceptable fitting on the entire Force-CMOD curves of several specimens does not necessarily predict accurately the peak loads [24], see also Fig. 8.

In the previous identification procedure the same value of internal length $l_{c}$ is used for the different specimens. In the damage model, $l_{c}$ is related to the FPZ width. However, recent experimental studies have shown that the FPZ width varies with the specimen size [25-28]. Furthermore, other studies explored the possibility of an evolving internal length arriving sometimes to contradictory conclusions [29-33] (i.e. the internal length should increase, decrease or stay constant).

Finally, Iacono and co-workers [24] have shown that even when using an inverse analysis to identify the model parameters, calibration based on three points bending experimental data does not provide acceptable predictions for tensile tests.

\subsection{Size effect and global fracture parameters}

The experimental and numerical results are transported into the classical normalized size effect plot (Fig. 9). The size effect independent parameters according to Bazant size effect theory are shown in Table 3 . They are calculated in two different ways, from the numerical or the experimental results, and they are used to normalize the nominal strength and specimen size as shown hereafter.

In Fig. 9(a), the experimental and numerical results are normalized using the respective size effect independent parameters $\left(D_{0}\right.$ and $\left.B f_{t}\right)$ coming from computation. Bazant's Size Effect Law (SEL) is also plotted. The computed points are located on the size effect curve but on the Linear Elastic Fracture Mechanics (LEFM) (right) side. A strong size effect on the nominal strength is observed for both sets of model parameters. The results obtained for $l_{c}=15 \mathrm{~mm}$ present a relatively more brittle behavior (closer to the LEFM law) than the results for $l_{c}=99 \mathrm{~mm}$. In this figure, the numerical results are not in good agreement with the experimental results.

It can be seen that the normalization parameters $D_{0}$ and $B f_{t}$ coming from the experiments and the computations are not similar (Table 3). This may be the first reason of the disagreement between the experimental and numerical points on the size effect plot. The fracture energy $G_{f}$ obtained from the numerical results is lower and thus a more brittle behavior is obtained. The characteristic length $l_{c h}^{*}$ according to Hillerborg et al. [34] is also deduced. This characteristic length has already been used by Bazant and Pfeiffer [35] in order to determine the size of the fracture process zone. It should be noted that the computed values of $l_{c h}^{*}$ do not correspond to the internal length $l_{c}$ of the non-local model.

In Fig. 9(b), both experimental and computed results are normalized with the experimental $D_{0}$ and $B f_{t}$. Nevertheless, the numerical results do not follow Bazant's Size Effect Law; they show instead a steep decrease in the nominal strength compared to the experimental results. 

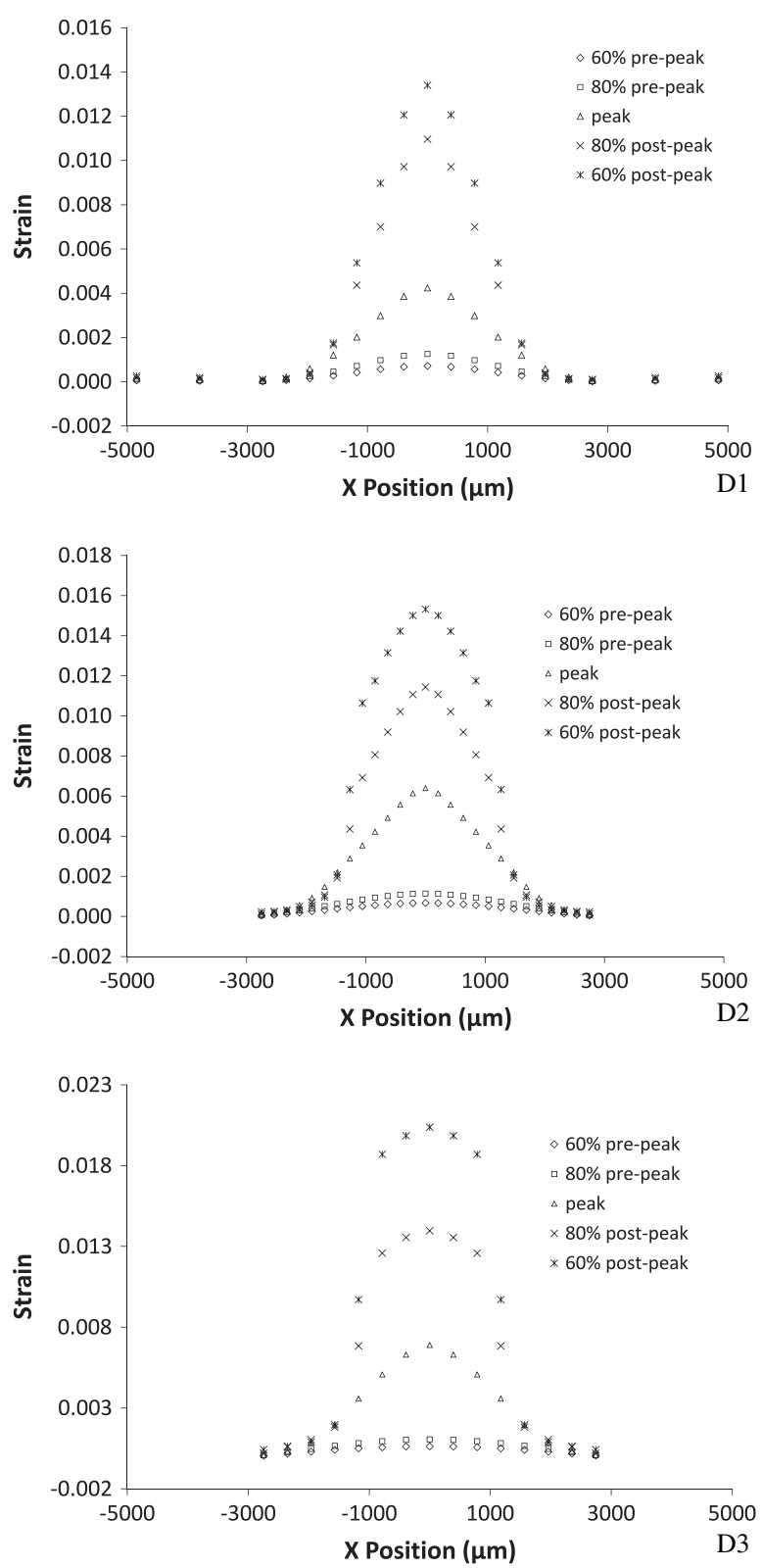

Fig. 11. Numerical strain profiles $\left(\varepsilon_{\mathrm{xx}}\right)$ for $l_{c}=15 \mathrm{~mm}$ at front of the notch in D1, D2 and D3 beams.

From the above discussion it can be concluded that the experimental size effect is not well reproduced by the numerical results and this is independent of the chosen normalization procedure.

\subsection{Evolution of the damage variable and strain mapping}

The evolution of the internal damage variable $d$ is studied hereafter. Fig. 10 presents the distribution of damage for the D2 specimen at peak load and at the tail of the F-CMOD curve. Results are presented for $l_{c}=99 \mathrm{~mm}$ and $l_{c}=15 \mathrm{~mm}$. The red square on the figure represents the area within a distance $l_{c}$ from the center line of the beam.

It is obvious that the width of the localization zone increases for higher values of the internal length. In Fig. 10(a and b) where $l_{c}=99 \mathrm{~mm}$, the width of damage zone grows as the beam is further loaded. At peak load or at the tail of the F-CMOD curve Fig. 10(a and b), the width of the damage zone is greater than the size of the strain localization zone obtained experimentally (Figs. 3 and 4). Although the Force-CMOD curve (global level) is correctly reproduced (Fig. 8), results are not satisfactory at local scale in terms of damage profiles. In Fig. 10 (c and d) where $l_{c}=15 \mathrm{~mm}$, the width of the damage zone 

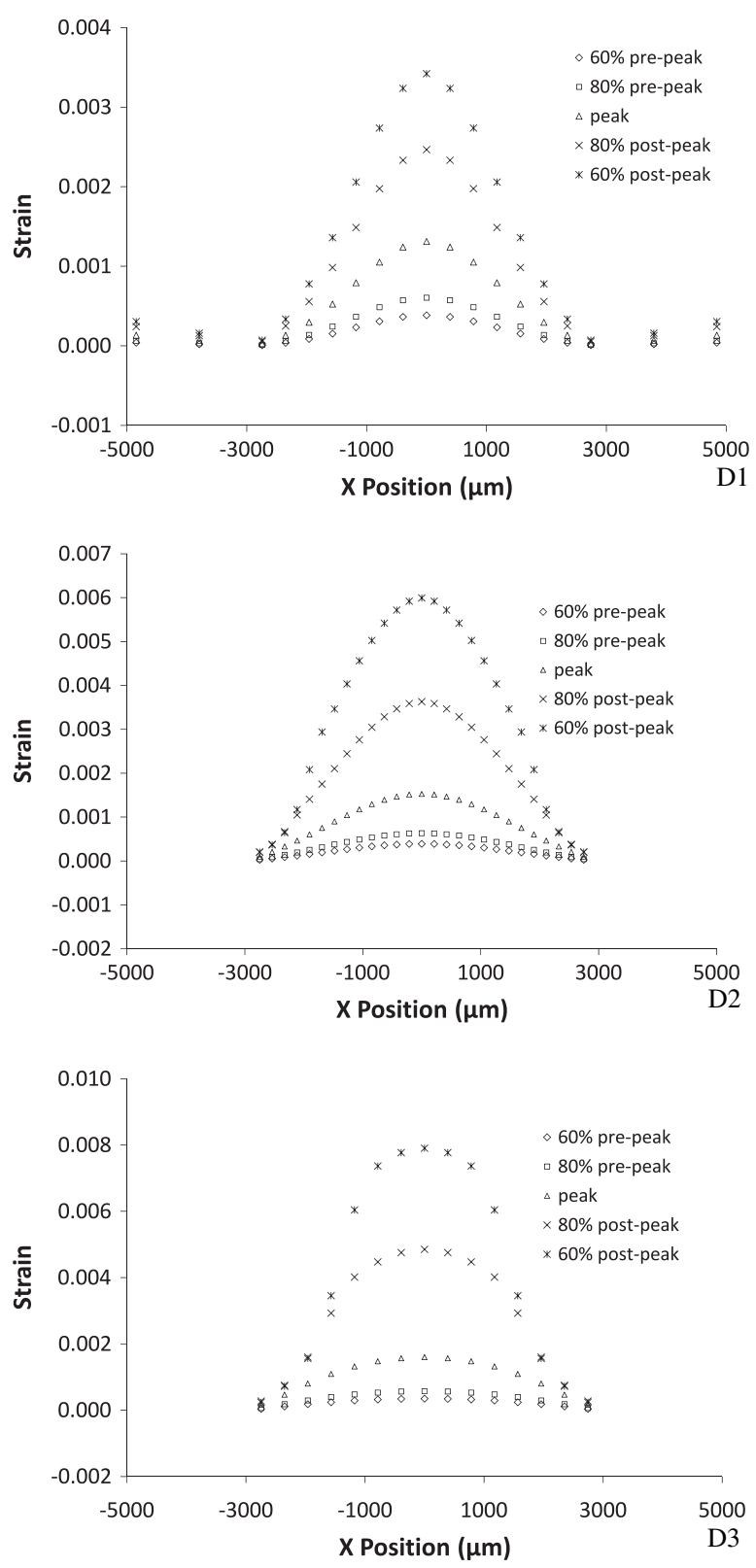

Fig. 12. Numerical strain profiles $\left(\varepsilon_{\mathrm{xx}}\right)$ for $l_{c}=99 \mathrm{~mm}$ at front of the notch in D1, D2 and D3 beams.

increases slightly with the loading but remains localized in a zone that corresponds better to the experimental strain. In other words, a $l_{c}=15 \mathrm{~mm}$ provides numerical results closer to the actual width of the localized zone, as can be seen from the evolution of the experimental strain profiles (Fig. 4).

The evolutions of the numerical axial strain profiles for $l_{c}=15 \mathrm{~mm}$ and $99 \mathrm{~mm}$ are plotted in Figs. 11 and 12 for the different beam sizes. It can be seen that the numerical strain localization zone remains almost constant. Furthermore, a bigger value of $l_{c}$ corresponds to a wider strain localization zone.

\subsection{Crack opening profiles}

The experimental and numerical crack opening profiles for the three beams, the two material sets and at different loading stages are presented in Fig. 13. As described in Section 2.2, the experimental profiles are calculated from the digital images considering the sum of the horizontal displacements of points at a distance $5 \mathrm{~mm}$ on either side of the crack. The same idea is adopted to calculate the numerical crack opening profiles: Crack openings are calculated as the relative (horizontal) displace- 

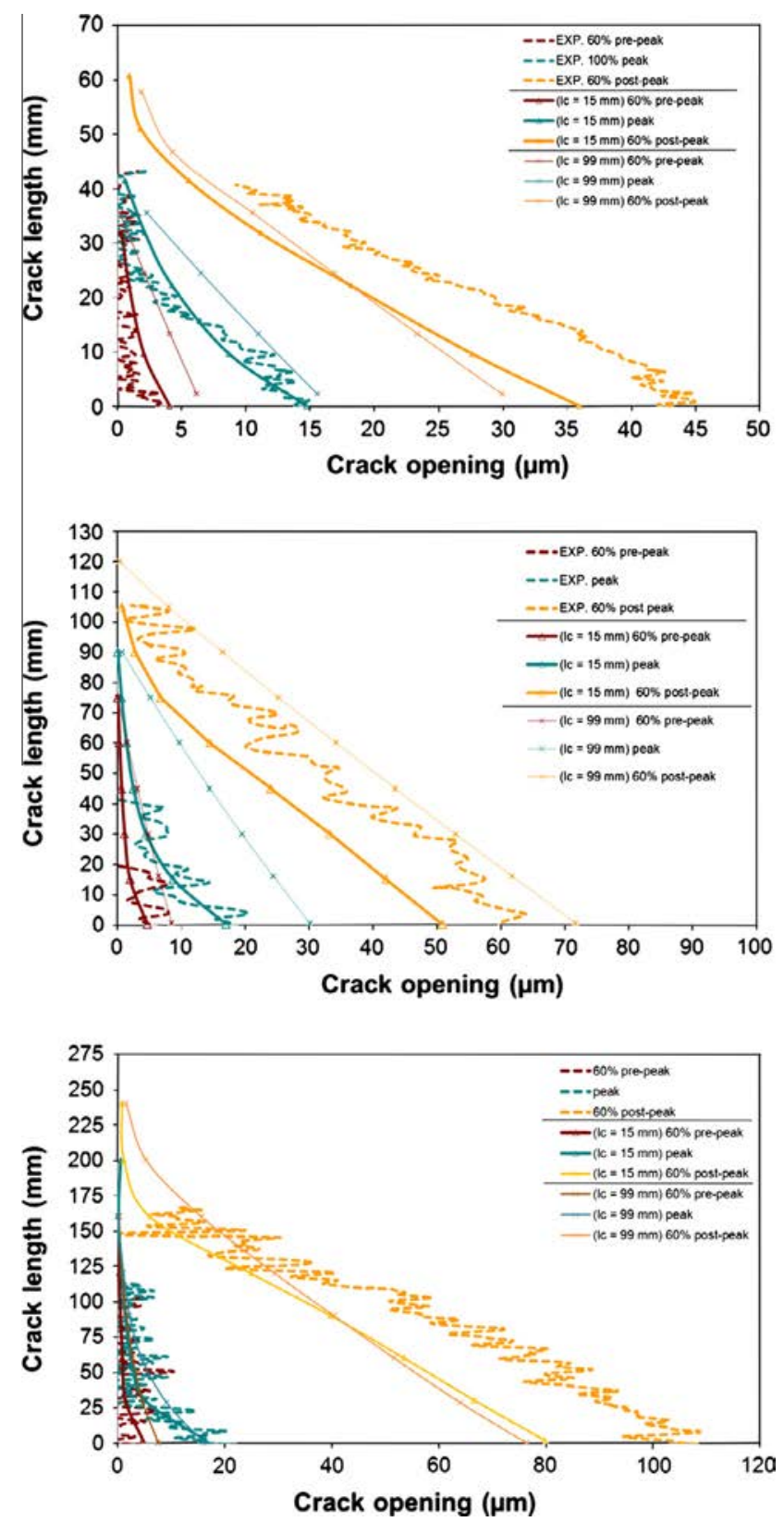

Fig. 13. Experimental and numerical crack opening profiles at different loading steps and for two material parameter sets (a) D1 beam, (b) D2 beam and (c) D3 beam.

ment field between the nodes of the finite element mesh situated on either side of the localized damage zone. This simplified method seems adequate when the behavior is mainly uni-dimensional (as is the case for beam structural elements) and the boundaries of the obtained localization zones can be clearly distinguished in the finite element mesh. However, other techniques that take into account displacement continuities (e.g. XFEM - Extended Finite Element method) can be more suitable to calculate the crack width $[11,12]$.

The characteristic length has an influence on the results, as it is shown in Fig. 13(a-c). For $l_{c}=15 \mathrm{~mm}$, the profile can be approximately divided into two straight lines with a smooth transition between them. Results fit better the experimental results at the pre-peak and peak regimes than for $l_{c}=99 \mathrm{~mm}$. Nevertheless, at the post-peak regime the numerical crack length is bigger than the experimental crack length. As the specimen progresses in the post-peak regime, discrepancy increases for both values of characteristic lengths and results are no longer satisfactory. This can also be seen in the global 


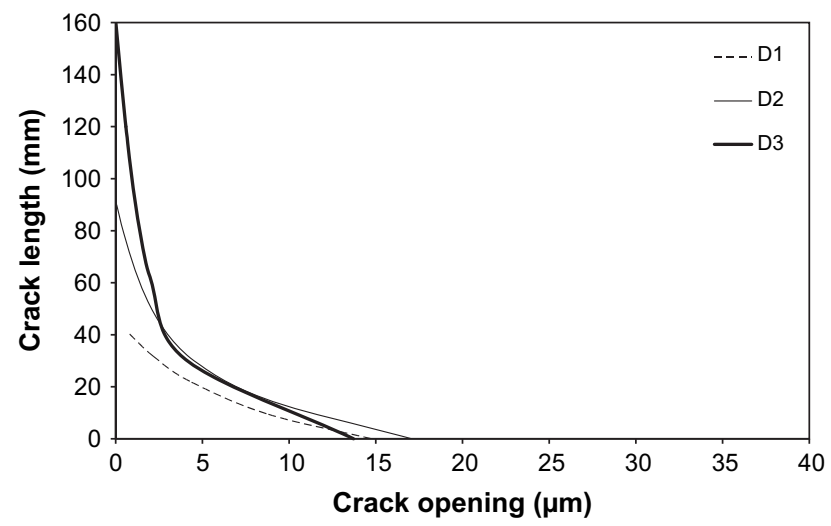

Fig. 14. Size effect on crack opening profiles at peak load for three specimens $\left(l_{c}=15 \mathrm{~mm}\right)$ (numerical results).

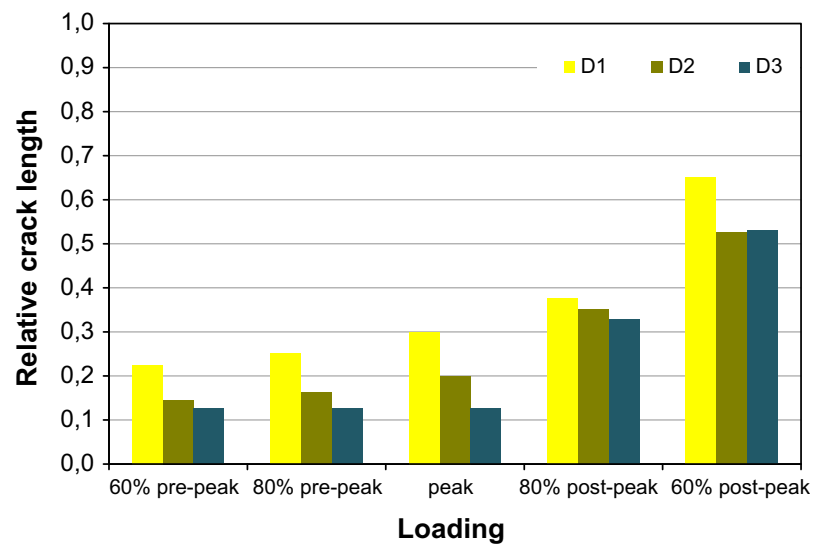

Fig. 15. Evolution of relative crack length at different loading steps for D1, D2 and D3 specimens (numerical results).

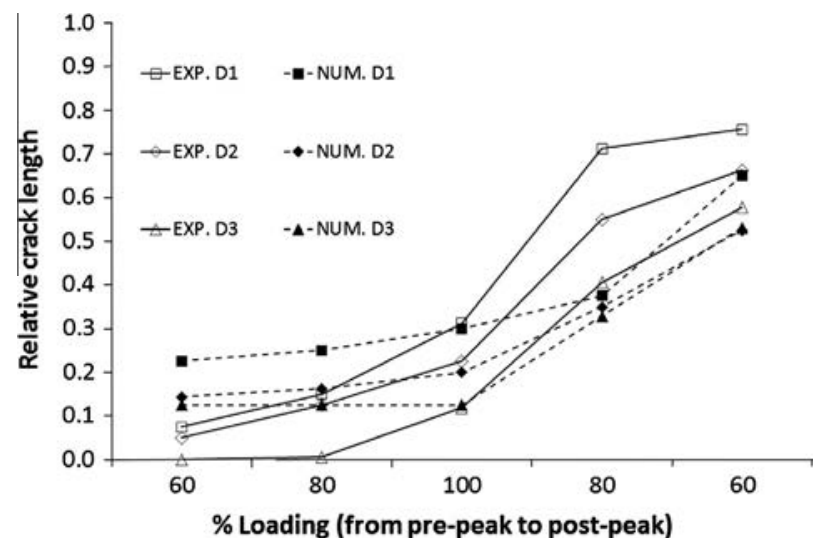

Fig. 16. Evolution of relative crack length with loading steps for D1, D2 and D3 specimens (experimental and numerical results).

F-CMOD curves, where the agreement between experimental and numerical curves decreases for high values of CMOD (Fig. 8).

\subsection{Size effect on the crack opening profile}

The influence of the beam dimensions (size effect) on the crack opening profiles computed numerically is analyzed hereafter. Fig. 14 presents the crack opening profiles at peak load for the three beams and for $l_{c}=15 \mathrm{~mm}$. It is observed that the 
lower parts of the crack opening profiles are practically the same for all three sizes. This is in accordance with the experimental findings i.e. specimens of geometrically similar sizes show the same crack opening profiles at peak load.

\subsection{Size effect on the relative crack length}

The crack length can be approximately derived from the numerical crack opening profiles assuming a linear interpolation of the lower (initial) part. The evolution of the (numerical) relative crack lengths for the three different sizes of the specimens is presented in Fig. 15. It can be observed that although the trend is correct, the computed relative crack length values do not agree with the experimental ones (Figs. 2 and 16). Furthermore, when the specimen size increases the relative crack length at peak is found decreased and not constant as assumed in the original version of the Bazant Size Effect Law [16]. This last result is in accordance with the experimental data (Fig. 2).

\section{Conclusions}

In this paper, experimental and numerical investigations of the influence of size effect on crack opening, crack length and crack propagation are presented. An isotropic non-local strain softening damage model is adopted. The choice of the internal length and other model parameters is done by inverse calibration using the Levenberg Marquardt algorithm and the procedure proposed in [13]. However here, not only global (Force-CMOD) but also local results (COD profiles, damage localization zone, strain localization zone and relative crack length) are considered to check the advantages and limitations of the approach.

The damage mechanics model is able to reproduce strain localization but not the cracking itself. Information about crack opening profiles is thus extracted using a simplified post-processing method. Crack opening is calculated as the relative (horizontal) displacement field between the nodes of the finite element situated on either side of the localized damage zone.

The main conclusions are summarized hereafter:

- Experimental size effect, as seen in the size effect curve, is not well captured by the numerical model.

- The evolution of the relative crack length is not well captured by the adopted numerical model.

- Different initial parameters adopted in the optimization procedure suggested in [13] can provide different characteristic lengths that may be outside the range proposed in [13].

- Different characteristic lengths can provide similar global results (Force-Notch Mouth Opening curves) and comparable crack opening profiles especially in the pre-peak regime. However, local results in terms of damage variable distributions and strain localization zone may be unrealistic.

- A characteristic length situated outside the range proposed in [13] can sometimes lead to better global and local results.

- The characteristic length should be calibrated based on the width of the localized zone and not on the width of the crack (a realistic prediction of strains is therefore crucial).

- The estimation of a single set of parameters that provides an acceptable fitting of the entire Force-Notch Mouth Opening curves of several specimen sizes do not necessarily correspond to a correct prediction of the peak loads.

- In the original version of the size effect law proposed by Bazant [16], the relative crack length at peak load in concrete specimens of varying sizes is assumed constant. This is clearly not verified in this study (neither from the numerical simulations or the experimental results).

- Specimens of geometrically similar sizes may show comparable crack opening profiles at their peak loads while the relative crack length decreases when the specimen size increases.

Similar conclusions can be found in the work presented in [24,36]. The non-local damage theory provides certainly efficient numerical solutions for localization problems. However, our understanding of the internal length parameter and its evolution is unsatisfactory and further studies are certainly needed, especially for size effect phenomena.

\section{Acknowledgements}

The support of the CEOS.fr (Comportement et Evaluation des Ouvrages Spéciaux Fissuration Retrait) and the ANR MEFISTO (Maîtrise durable de la Fissuration des Infrastructures en béton, ANR 2008 Sustainable Cities Program, Project No.: VD08_323065) French national programs are gratefully acknowledged. The first author would like to thank the Higher Education Commission of Pakistan for the financial support (PhD grant).

\section{References}

[1] Jirásek M. Objective modeling of strain localization. Rev Française Gén Civil 2002;6:1119-32.

[2] De Borst R, Mühlhaus H. Gradient dependent plasticity: formulation and algorithmic aspects. Int J Numer Meth Engng 1992;35:521-39.

[3] Vardoulakis I, Sulem J. Bifurcation analysis in geomechanics. Blackie Academic and Professional; 1995.

[4] Fremond M, Nedjar B. Damage gradient of damage and principle of virtual work. Int J Solids Struct 1996;33(8):1083-103.

[5] Mindlin RD. Microstructure in linear elasticity. Arch Ration Mech Anal 1964;16:51-78.

[6] Germain P. The method of virtual power in continuum mechanics. Part 2: Microstructure. SIAM J Appl Math 1973;25(3):556-75. 
[7] Chambon R, Caillerie D, Matsushima T. Plastic continuum with microstructure, local second gradient theories for geomaterials, localization studies. Int J Solids Struct 2001;38:8503-27.

[8] Pijaudier-Cabot G, Bazant ZP. Nonlocal damage theory. J Engng Mech - ASCE 1987;113(10):1512-33.

[9] Matallah M, La Borderie C. Analyse critique des résultats du benchmark ceos.fr. Technical report, Projet MEFISTO (GT1-1); 15 th June 2009.

[10] Alam SY. Experimental study and numerical analysis of crack openings in concrete. PhD thesis, Ecole Centrale de Nantes; 2011. <http://tel.archivesouvertes.fr/tel-00669877>.

[11] Réthoré J, Tinnes JP, Roux S, Buffière JY, Hild F. Extended three-dimensional digital image correlation (x3d-dic). CR Méc 2008;336(8):643-9.

[12] Nguyen TL, Hall SA, Vacher P, Viggiani G. Fracture mechanisms in soft rock: identification and quantification of evolving displacement discontinuities by extended digital image correlation. Tectonophysics 2011;507:117-28.

[13] Le Bellégo C, Dubé JF, Pijaudier-Cabot G, Gérard B. Calibration of nonlocal damage model from size effect tests. Eur J Mech A - Solid 2003;22(1):33-46.

[14] RILEM Recommendation. Size-effect method for determining fracture energy and process zone size of concrete. Mater Struct 1990;23:461-5.

[15] Alam SY, Loukili A, Grondin F. Monitoring crack openings in concrete beams with different sizes using digital image correlation technique. Eur J Environ Civil Engng 2012;16(7):818-36.

[16] Bazant ZP. Size effect in blunt fracture: concrete, rock, metal. J Engng Mech - ASCE 1984;110(4):518-35.

[17] Mazars J. Application de la mécanique de I'endommagement au comportement non linéaire et à la rupture du béton de structure. PhD thesis, LMTUniversity Paris 6; 1984.

[18] <http://www-cast3m.cea.fr>.

[19] Bazant ZP, Pijaudier-Cabot G. Measurement of characteristic length of nonlocal continuum. J Engng Mech - ASCE 1989;115(4):755-67.

[20] Carmeliet J. Optimal estimation of gradient damage parameters from localization phenomena in quasi-brittle materials. Mech Cohes-Frict Mater $1999 ; 4(1): 1-16$.

[21] Mahnken R, Kuhl E. Parameter identification of gradient enhanced damage models with the finite element method. Eur J Mech A - Solid $1999 ; 18(5): 819-35$.

[22] De Borst R, Pamin J. Gradient plasticity in numerical simulation of concrete cracking. Eur J Mech A - Solid 1996;15(2):295-320.

[23] Di Prisco M, Ferrara L, Meftah F, Pamin J, De Borst R, Mazars J, et al. Mixed mode fracture in plain and reinforced concrete: some results on benchmark tests. Int J Fract 2000;103:127-48.

[24] Iacono C, Sluys LJ, Van Mier JGM. Calibration of a higher-order continuum model using global and local data. Engng Fract Mech 2008;75(16):4642-65.

[25] Otsuka K, Date H. Fracture process zone in concrete tension specimen. Engng Fract Mech 2000;65(2-3):111-31.

[26] Duan K, Hu X, Wittmann FH. Explanation of size effect in concrete fracture using non-uniform energy distribution. Mater Struct 2002;35:326-31.

[27] Duan K, Hu X, Wittmann FH. Scaling of quasi-brittle fracture: boundary and size effect. Mech Mater 2006;38(1-2):128-41.

[28] Duan K, Hu X, Wittmann FH. Boundary effect on concrete fracture and non-constant fracture energy distribution. Engng Fract Mech 2003;70(16):2257-68.

[29] Pijaudier-Cabot G, Haidar K, Dubé JF. Non-local damage model with evolving internal length. Int J Numer Anal Met 2004;28(7-8):633-52.

[30] Voyiadjis G, Abu Al-Rub R. Gradient plasticity theory with a variable length scale parameter. Int J Solids Struct 2005;42(14):3998-4029.

[31] Kotronis P, Al Holo S, Bésuelle P, Chambon R. Shear softening and localization: modelling the evolution of the width of the shear zone. ACTA Geotech 2008;3(2):85-97.

[32] Challamel N, Lanos C, Casandjian C. On the propagation of localization in the plasticity collapse of hardening-softening beams. Int J Engng Sci 2010;48(5):487-506

[33] Giry C. Modélisation objective de la localisation des déformations et de la fissuration dans les structures en béton armé. PhD thesis, Université de Grenoble; 2011. <http://tel.archives-ouvertes.fr/tel-00697769>.

[34] Hillerborg A, Modéer M, Petersson PE. Analysis of crack formation and crack growth in concrete by means of fracture mechanics and finite elements. Cem Concr Res 1976;6(6):773-81.

[35] Bazant ZP, Pfeiffer PA. Determination of fracture energy from size effect and brittleness number. ACI Mater J 1987;84:463-80.

[36] Iacono C, Sluys LJ, Van Mier JGM. Estimation of model parameters in nonlocal damage theories by inverse analysis techniques. Comput Methods Appl Mech Engng 2006;195(52):7211-22.

[37] Mindess S. Fracture process zone detection. In: Shah SP, Carpinteri A, editors. Report RILEM TC 89-FMT: fracture mechanics test-methods for concrete. London/New York: Chapman \& Hall; 1991. p. 231-61.

[38] Mihashi H. States of the art and a view of the fracture mechanics of concrete. J JCI 1987;25(2):14-25.

[39] Kocur GK, Saenger EH, Vogel T. Elastic wave propagation in a segmented X-ray computed tomography model of a concrete specimen. Constr Build Mater 2010;24:2393-400.

[40] Choi S, Shah SP. Measurement of deformations on concrete subjected to compression using image correlation. Exp Mech 1997;37:307-13.

[41] Corr D, Accardi M, Graham-Brady L, Shah SP. Digital image correlation analysis of interfacial debonding properties and fracture behavior in concrete. Engng Fract Mech 2007;74:109-21.

[42] Skarzynski L, Syroka E, Tejchman J. Measurements and calculations of the width of the fracture process zones on the surface of notched concrete beams. Strain 2011;47:319-32. 